\title{
Overview of Evolving Changes in Cuba's Health Services
}

\author{
Luisa Iñiguez DrSc
}

Translated from the Spanish and reprinted with permission from the Revista Cubana de Salud Pública, [online] Vol. 38, No. 1, Jan-Mar 2012. Original available at: http://scielo.sld.cu/scielo.php?script=sci_arttext\&pid=S0864-34662012000100011\&lng=es\&nrm=iso\&tlng=es

\begin{abstract}
This paper describes the evolution of basic indicators of health services, human resources, and infrastructure, starting with a general account of processes under way since the mid-1990s aimed at health sector recovery and focused on improving quality of service, system efficiency and effectiveness, while maintaining equity. Using this background, a description is provided of objectives and essential elements of transformations currently under way in the national health system, based on processes of reorganization, consolidation and regionalization of services. Finally, implications of territorial redistribution for health system reform are discussed, focusing on tensions between rationalization and equity in real or perceived access.
\end{abstract}

KEYWORDS Health services, transformations, Cuba

Cuba is currently immersed in various processes assessing the country's most pressing problems, within which guidelines for economic and social policy have been adopted.[1] Numerous changes have occurred as a result and others are in the offing, among them, transformations in the national health system (NHS).

In the mid-1990s, the Ministry of Public Health (MINSAP, the Spanish acronym) began a new period of transformation in the sector, its goal to define main strategic lines and programs that would lead to system consolidation and modernization, including new methods and styles of work. Since that time, increasing health expenditures have limited spending in other public sectors.[2]

At the start of this millennium, Cuba's government implemented numerous social programs as part of what it called the "Battle of Ideas;" these included actions designed for NHS recovery and improvements, under the umbrella of what was termed a health sector revolution. In late 2010 , the rollout was announced of the "reorganization, consolidation and regionalization of health services," foreshadowed in a December 2009 speech by President [Raul Castro], who stated that "... without affecting quality of health [care], provided at no cost to all citizens-and even improving it-expenditures can be reduced appreciably."[3]

Bearing in mind these premises, this paper will attempt to provide a contextualized overview of the recent evolution and current status of health services in Cuba, by addressing several questions: How is the sectoral revolution begun in the past decade manifest in current transformations? What main obstacles may be faced in meeting the new objectives?

\section{DETERIORATION OF SERVICES}

\section{AND HEALTH SECTOR REVOLUTION}

The direct and indirect effects of the grave economic crisis in Cuba in the early 1990s caused physical deterioration of facili- ties, serious supply shortages, deficiencies in professional performance and a lack of managerial training in health system management at the health unit level. This was accompanied by an increase in demand for hospital services and growing public dissatisfaction, even with emergency services.[1,4] The results of a 1990 national MINSAP survey on patient satisfaction with medical services were by no means favorable: approximately $70 \%$ of the population was somewhat satisfied and $10.6 \%$ was dissatisfied, a situation that deteriorated in the ensuing years.

In this regard, Dr Julio Suárez noted in 1997:

"The impact of the crisis on health services poses challenges that are difficult to overcome in a country with a universal, free health system; a population accustomed to making extensive use of these services, including those employing advanced technology; and a situation where access to foreign credits on the one hand, and to markets for drugs, supplies, and medical equipment on the other, is hindered by the [US] blockade, driving up their cost and making them harder to obtain."[5]

In the mid-1990s, MINSAP began conducting studies to assess the situation in the NHS and outline strategies for sectoral recovery centered on improving service quality, efficiency and effectiveness, and on maintaining equity.[1]

The following areas were given priority: reorientation of the health system toward primary care; revitalization of hospital care; revival of cutting-edge technology programs and research institutes; development of the Natural and Traditional Medicine Program; and greater attention to emergency, dental and optical services. Top priority was given to programs for maternal and child health, chronic non-communicable diseases, communicable diseases and older adult health. The health sector revolution programs were designed in the early 2000s, aimed at improving the system in general and primary care in particular; and previously initiated reform processes were revived. These programs reaffirmed the need for changes in the NHS's organizational structure, particularly for ambulatory care, health services and [national] programs.[6]

One step in implementing these changes was the Polyclinic Reconstruction and Modernization Program, which included bringing a number of services closer to the population, adapting services to the health situation of each locale, training and continuing education for staff, upgrading equipment and introducing new technology.[5] Thus, [community-based] polyclinics were repaired and their services expanded through technology transfer from secondary and tertiary care levels (general and specialized hospitals) to the primary care level on a hitherto unprecedented scale.[7]

As a result, polyclinics were able to offer an average of 20 services-though some had over 30-such as rehabilitation, radiol- 
ogy, ultrasound, optometry, endoscopy, thrombolysis, emergency and trauma care, family planning, dental emergencies, vaccinations, clinical laboratories, and care for diabetics and older adults. These were in addition to specialist services in internal medicine, pediatrics, obstetrics and gynecology, dermatology, psychiatry, and cardiology. Repair and refurbishing or introduction of high-tech equipment also benefited secondary-level care included in another program under way for hospital reconstruction and modernization.

Along with these changes, family doctor-and-nurse offices were gradually reduced in number and caseloads from several offices consolidated into one. Although coverage was maintained at $100 \%$, caseload increased, resulting in overload for physicians and nurses and seriously affecting care provided, particularly public perception of its quality. There was no change in priority accorded to some programs, such as the National Maternal-Child Health Program (PAMI, the Spanish acronym), but the practice of essential activities was weakened, such as neighborhood outreach and house calls, particularly regular visits by the doctor and nurse to vulnerable people [in their catchment area].

Some consider the reduced number of family doctor-and-nurse offices and their service consolidation was provoked by the mass exodus of physicians for international cooperation abroad; others associate it not with lack of physicians but with serious organizational problems faced by the Family Doctor-and-Nurse Program (PMEF, the Spanish acronym).[8,9] The reduction was also accompanied by infrastructural deterioration of the family doctorand-nurse offices and supply scarcities.

As a consequence, public dissatisfaction was growing, related to service instability, wait times, and physician absence because of administrative duties or new teaching responsibilities, all coupled with "adapting" to newly assigned family doctors in neighborhoods. This situation was complicated by total or partial closure of hospitals and therefore of more complex services, as these were being repaired and re-equipped as part of the national program [mentioned above]. Perceptions were even more negative because of comparisons with prior care, especially because the family doctor's office was envisioned as the gateway to the system for more complex and specialized care, much of which would now be available at the polyclinics.

Doctor visits per capita dropped by two from 2002 to 2006, a decrease even greater than the one in the 1990s. It should be noted that the decrease was even sharper than that of 1993, when incidence of several diseases increased, requring intensification of active case-finding that might have influenced the decrease in office visits (Figure 1).

In 2008, a general reorganization of primary care was launched, considering the situation referred to above and the fact that caseloads for family doctor-and-nurses had risen to 2500 people. A temporary reclassification of these offices into types I, II, and III was established, based on hours of operation and staffing, location and patient access to other health facilities. Type I offices were open eight hours a day during the work week, half a day on Saturdays, and had evening hours one day a week, with a multidisciplinary team that cared for an average of 2500 to 3000 people. Type II had eight hours of family nursing staff to serve the population, working under an [offsite] physician. Type III, located in the most remote sites, had a physician and nurse 24 hours a day.
Figure 1: Outpatient and emergency room visits

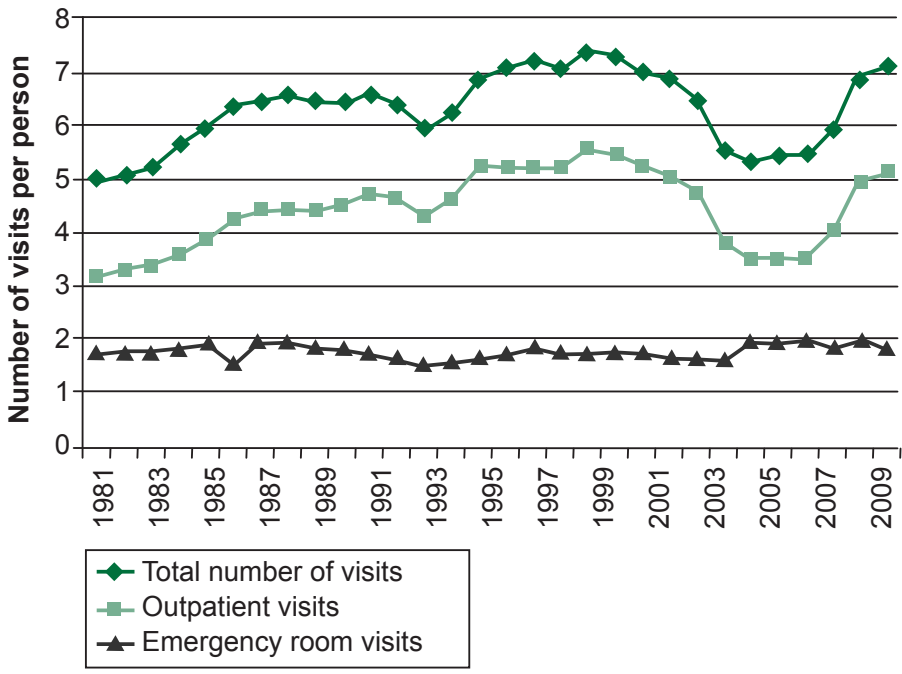

Source: Health Statistics Yearbook, 2009 and 2010. National Health Statistics Division, Ministry of Public Health, Havana

The upswing in the number of outpatient visits that began in 2008 suggests the positive effect of this reorganization.

At the same time as these turning points, surgical activity, which had been seriously affected since the 1990s, continued to drop: in 2006 there were 58,000 fewer surgeries than the previous year. This fact implies a loss of system capacity for meeting surgical demand while refurbishing and modernization programs were under way in health care institutions, in the context of limited surgical resources.

Several facilities caring for vulnerable groups such as pregnant women and older adults changed the availability of services, where there also may have been reduced demand. The number of residents in homes for the aged remained stable during the 1990s and the early 2000s, and then dropped slightly in 2003 by fewer than 300 older adult beneficiaries (Figure 2). In contrast, the number of day-boarders grew sharply during the same period.

\section{Figure 2: Older adults in MINSAP homes for the aged}

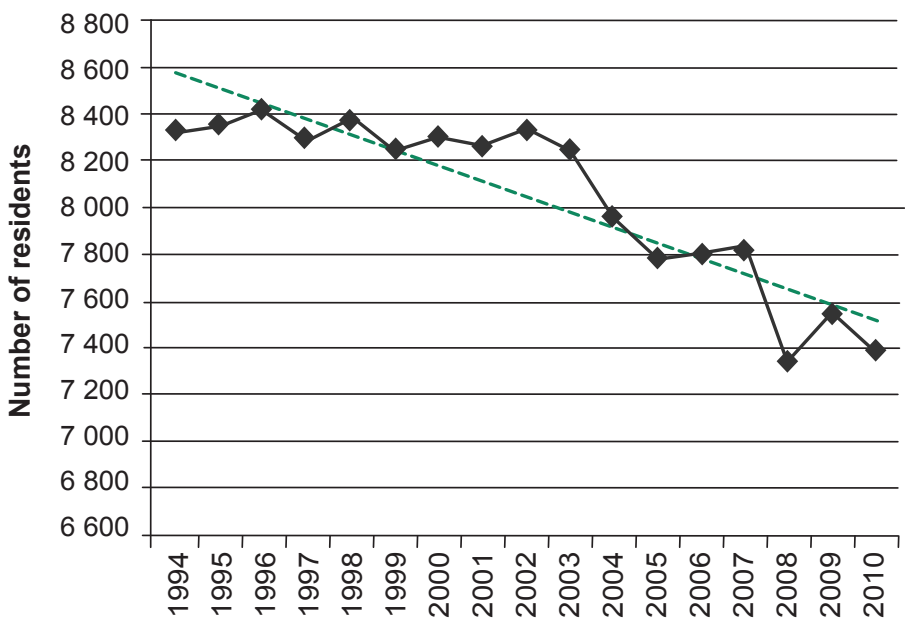

Source: Health Statistics Yearbook, 2009 and 2010. National Statistics Division, Ministry of Public Health, Havana 
Other resources and services for these population groups continued in institutions such as senior centers, providing comprehensive care for older adults, and local service-provision variants, including integrated in-home social services for the most vulnerable adults.

Maternity homes had been established to provide pregnant women at risk with accommodation close to hospitals. In addition to antenatal care, these homes ensure remote and [at-risk] women receive a good diet and provide them with health education focused on encouraging breastfeeding and teaching child care. The number of pregnant women in maternity homes initially increased, before beginning to drop in 2002, reaching the lowest point in 2006, with just under 70,000 residents; after this, an exponential rise in maternity home admissions (including day boarders) began that reached 52.8 per 100 live births by 2010 (Figure 3).

Figure 3: Pregnant women in maternity homes

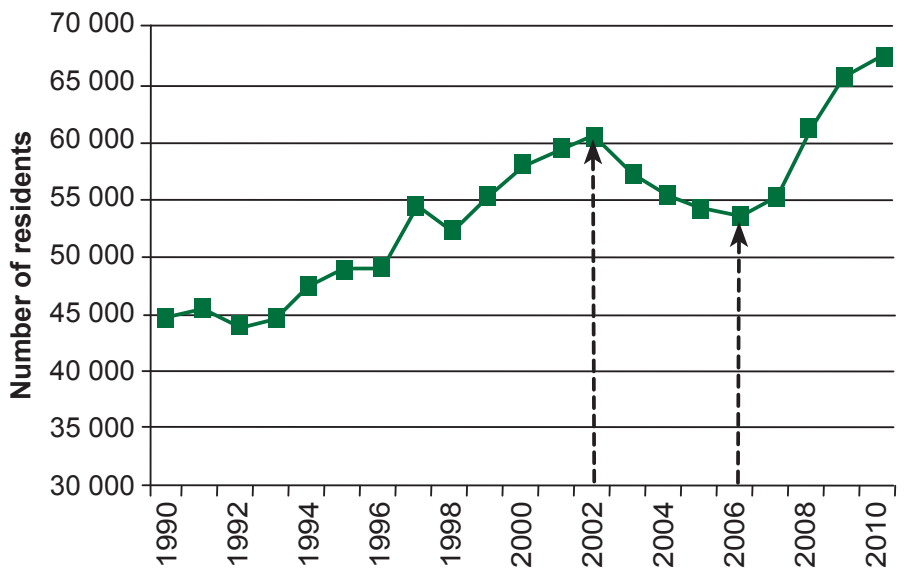

Source: Health Statistics Yearbook, 2009 and 2010. National Statistics Division, Ministry of Public Health, Havana

This increase in maternity home use could be due to several factors, including an alternative consisting of a day-boarding system, the increased number of births in the last two years of the period analyzed, and the priority PAMI continues to place on this practice of proven effectiveness.

The priority afforded the health sector since 1959 has meant a substantial increase in budgeted expenditures, particularly in the 2000s and more steeply from 2006 forward, consistent with the consolidation of the programs previously described. In 2009, spending reached a high point of 440.30 Cuban pesos per capita (Figure 4).[10]

The number of health workers increased in the 1980s with implementation of the Family Doctor-and-Nurse program; a new surge began in 2002, observed particularly in 2006, and explained essentially by incorporation of workers to staff new or expanded polyclinic services. This was also the result of initiation of a stepladder training model for [certain] health professionals that permitted them to join the workforce after their first year of studies. A further factor was a modest wage increase in mid 2005.

Thus, education of human resources for health expanded greatly in the 1980s, then contracted starting in the late 1990s, and again increased considerably from 2006 , with 26,600 students graduating from higher education in various fields in 2010. This [number of graduates] is due fundamentally to the number of professionals trained in health technologies (Figures 5, 6).[10]
Figure 4: Health workforce and per capita health expenditure trends in Cuba, 1976-2010
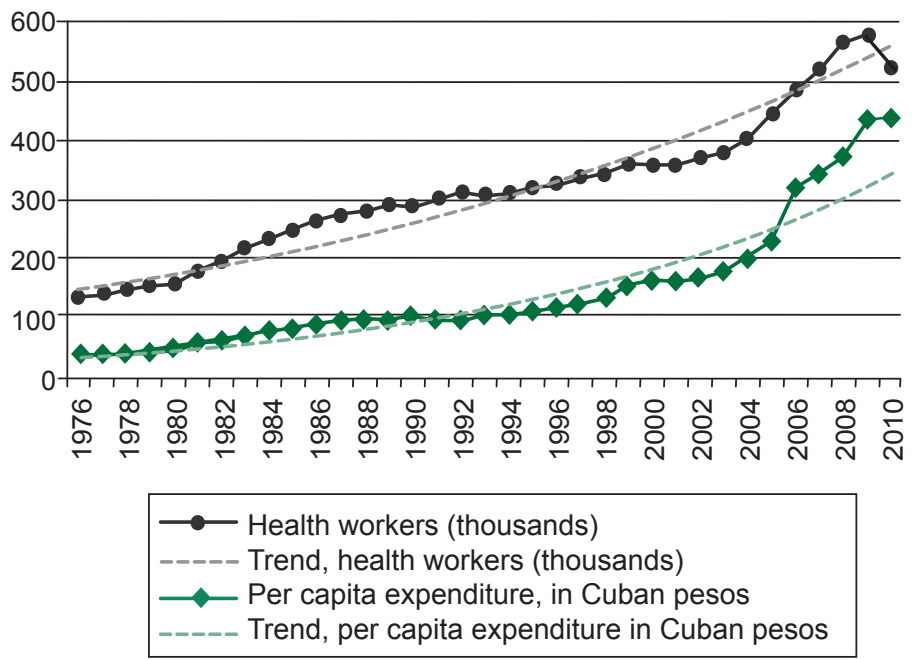

Source: Health Statistics Yearbook, 2009 and 2010. National Health Statistics Division, Ministry of Public Health, Havana

Figure 5: Education of human resources for health, 1990-2010

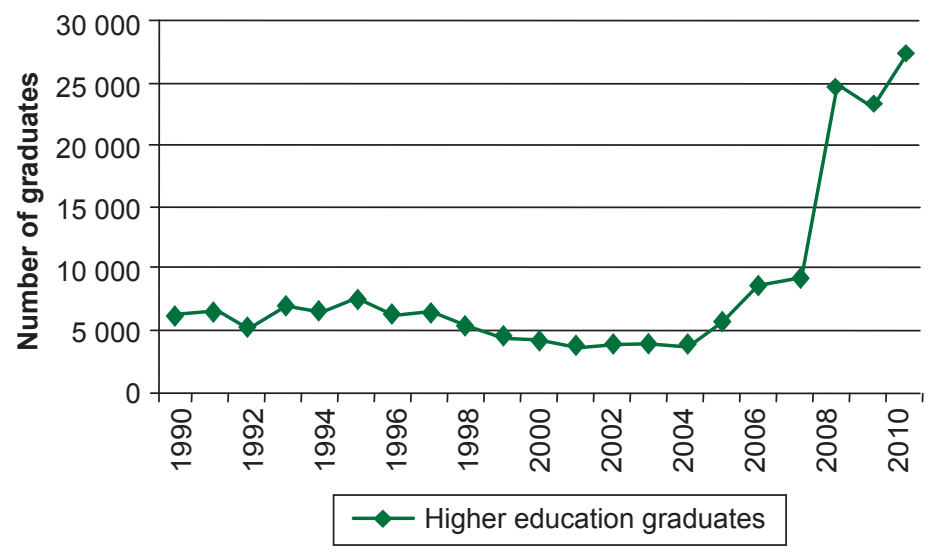

Source: Health Statistics Yearbook, 2009 and 2010. National Health Statistics Division, Ministry of Public Health, Havana

A breakdown by occupation for 2009 shows the highest density of health workers in [nursing and allied health] occupations, with 119 mid-level technicians per 10,000 population and 86.5 nurses per 10,000 population. That same year, there were 66.6 physicians per 10,000 population and 10.3 dentists per 10,000 population. At the close of 2009 , there were 74,880 active physicians, of whom $73 \%$ were specialists. The greatest number of physicians were those trained in family medicine $(45 \%$ of the total), of whom $75 \%$ had completed residencies in this field, followed by those working in health services organization and administration (approximately $20 \%$ of the total), $5 \%$ of whom had specialty training in health services management. High proportions of physicians were also specialized in internal medicine, obstetrics and gynecology, and pediatrics.[10]

Accompanying these processes were changes in service indicators during the first decade of the new millennium, coinciding with the launch of new programs of the revolution in the health sector, accelerating growth in total number of workers, per capita expen- 
Figure 6: Education of human resources for health by universitylevel profession

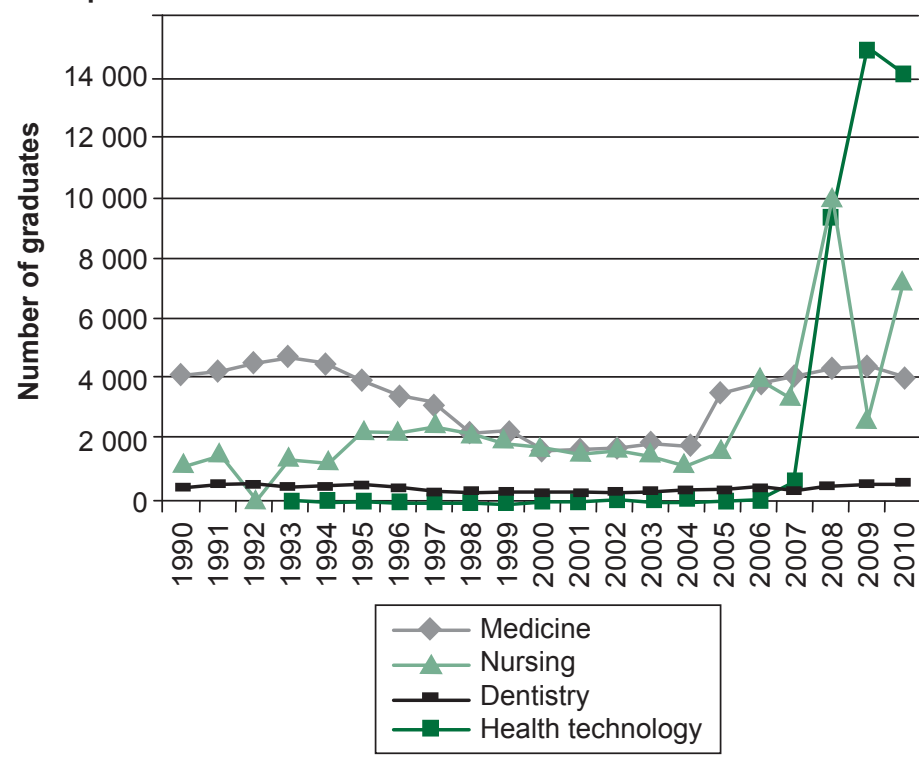

Source: Health Statistics Yearbook, 2009 and 2010. National Health Statistics Division, Ministry of Public Health, Havana

ditures and training in some specialties, all in the context of a sustained increase in physician:population ratio, which reached 68.1 physicians per 10,000 population in 2010.[11]

The pivotal points mentioned-downturn in the early 2000s and recovery starting in 2006-suggest the influence of implementing these programs, with regional variations, ranging from reduction in services offered or in demand, depending on the particular stage of health institution reconstruction and modernization.

As has been noted elsewhere, important international health indicators-such as infant mortality, under 5 mortality and incidence of infectious diseases-in general did not deteriorate during the most difficult years and even improved. This is explained not only by the ongoing priority afforded to the respective health care programs since creation of the NHS, but also to progress in aspects of living conditions in the past decade, although this was uneven across social groups.

Furthermore, the positive impact of polyclinic reconstruction and modernization programs and the increase in their services can be seen in the proportional shift in patient visits to them: in 2010, polyclinics were the site of close to $90 \%$ of total outpatient visits and $65 \%$ of all emergency visits.[11]

A final and sensitive aspect is at work in the web of components and processes in which programs to restore quality of health services in the country evolved. These are more difficult phenomena to measure, arising from the subjective-objective duality of processes that produce secondary effects such as low employee morale and perceptions of inequality by workers in the sector. Although it is certainly true that workers' spiritual motivations need to be more fully addressed to reach full realization of public health's social mission,[5] a deeper analysis is also needed of the material living and working conditions of health professionals and the health workforce in general.
It is well known that the majority of Cuban physicians who have neither served internationally nor have the benefit of supplementary income sources-such as family assistance or remittances-generally experience economic constraints similar to those of other workers in the country (professional or otherwise). This results in an acknowledged gap between supply and demand, or demand without supply, and many other limitations in ability to satisfy basic or traditionally met needs, or to find new ways to satisfy old needs. These situations, although not exclusive to Cuba, are infrequent in other countries, where professions with significant social recognition-medicine, nursing and rehabilitation specialists, among others - frequently constitute a strata with an income advantage.

\section{CURRENT TRANSFORMATION IN THE NHS: FOCUS ON DISTRIBUTION AND EQUITY}

MINSAP recently drafted a document on NHS transformations, which we will use to analyze current proposals.[12]

The document states that the transformations will permit:

"...more efficient and rational use of the significant and costly resources at our disposal, especially technological resources, as well as their ongoing availability, which will ensure the sustainability of health services."

Although the initial impetus was undoubtedly economic, clearly other elements were also considered, since as stated in the document, the transformations are intended to address the "immediate need for higher levels of efficiency and quality."[12] Consistent with this, the first health sector strategic direction adopted recently in the country's general economic and social policy guidelines calls for "enhancing quality of services and efficient use of resources, with a subsequent reduction in costs." According to official figures, during the first decade of the new millennium, the health care budget did not decrease; [however], in 2010 a decrease of slightly over 10 million pesos was registered.

Explicit in the transformations is the premise that management structures be reorganized to meet specific needs stemming from the health situation ins each locale-the number, qualifications and experience of personnel strictly corresponding with needs, to guarantee efficient services. Along with the anticipated workforce reduction, managers at every level of leadership are expected to have come up through the ranks of the health system before being tapped for higher positions, as well as to have the required qualifications and experience. The document emphasizes the importance of physicians' application of clinical skills and epidemiological methods as the main guarantors of quality health care, tools it considers underutilized as both doctors and the public shifted priority and preference to diagnostic technologies.

Service regionalization is identified as key to maintaining the health sector's technical and material achievements, given the country's economic situation. This effort is based on territorial redistribution of services to concentrate specialty services to improve quality and efficiency.[12]

This analysis and resulting proposals led to a redistribution of services, particularly in primary care, most of which has been carried out in recent years in the framework of the health sector revo- 
lution, and include such services as rehabilitation, endoscopy, menstrual regulation, imaging, minor surgery and urgent care. The guidelines state that services should be relocated when there is demonstrated underutilization, increasing the number of beneficiaries and of communities or municipalities in [newly defined] catchment areas.

Regionalization was one of the primary modifications made to a principle championed by the health sector revolution in the last decade of 'bringing services closer to people,' in light of the need for a rational distribution of services that would ensure their continued availability. Although this is posed as a way to ensure greater quality, the accessibility issue is a factor that could limit positive results expected from regionalization, in terms of satisfaction and other indicators.

Regarding distribution of [community-based] polyclinics, a reassessment is planned of activity levels and necessary human resources in facilities serving fewer than 5000 people. Where underutilization of resources or services is confirmed, the polyclinics will be converted into family doctor-and-nurse offices, redefining their functions according to population served. This is another sensitive consideration that could jeopardize equitable distribution.

Hospital services and occupancy rates will be assessed to adjust resources and staffing. In cases where maintaining services is considered unjustified, these will be consolidated or relocated. In fact, in some provinces such as Villa Clara, regionalization has already involved a reduction in the number of hospitals and their conversion to other functions, such as homes for the aged or polyclinics with beds.[13]

One important reorganization involves the $24 \%$ of municipalities in the country with only one health area, meaning a single polyclinic reporting to the municipal health department. The two administrations are now being merged, with the polyclinic assuming management of the municipal health system, eliminating duplication of functions. A health area is defined by geographic boundaries within which the resident population is entitled to receive comprehensive health care through a local polyclinic.

Transformations in family doctor-and-nurse care include changes in size of population served, number of offices providing regular services, and staff complement. The maximum population is established at 1500 persons to be served through both office visits and house calls/outreach. Thus, from an average population of 120 to 160 families served-maintained until 2004, followed by a mid-decade increase to over 600 families-now, each office will serve an average of 300 to 400 families.

It is striking that the number of families or individuals residing in a doctor's office or polyclinic catchment area, although certainly considered, is not, so far as we are aware, accompanied by a definition of geographic area served or of travel distance or time between services and where people live. These factors can be decisive in some contexts, particularly in rural or mountainous areas, or in communities negatively hit by recent economic events, such as closure of sugar mills, where transportation services are seriously affected.

On the other hand, revitalization of family medicine has been reported in the media, with the reopening of doctor's offices and a return to [lower] caseloads, with consequent restoration of some functions that had been seriously affected. This is undeniably an important way to improve availability of primary care services and to potentially improve public satisfaction with community-based services.[14,15] Such a process is underway in Havana, which in some cases is using the alternative of dividing family doctor-andnurse caseloads between two offices operating out of a single facility.

Another transformation is related to regionalization of ambulance services and changes in base locations. These measures immediately cut costs and increase oversight, but their effectiveness needs to be carefully monitored, given that ambulances are generally used for emergencies and delays in service can lead to crucial differences in outcomes.

The care pregnant women receive in maternity homes is being reorganized based on occupation rate (pregnant women per maternity home), distance to polyclinics with beds and rapid access to the corresponding obstetrical-gynecological hospital. A reduction in number of maternity homes is expected, accompanied by a downsizing of maternity care organizational structures.

As the assessment proceeds, it has been found that some maternity homes with only three-to-five bed capacity have an average of 20 workers and that some homes are close to facilities that can ensure care for pregnant women.[16] Consolidation of these homes has already led to a reduction in their number in places such as Villa Clara Province.[13]

One finding of particular interest comes from a reassessment of opportunities for entering several health careers, such as those in health technologies [laboratory technicians, x-ray technicians, etc.]. Findings indicate that one of the causes of the "excessive number of workers" is an increase in numbers training in some fields, particularly in health technology professions. This is explained by a failure to have taken regional needs into account when deciding how many students to accept in the corresponding educational institutions. Conversely, some geographic areas suffer from lack of services in some specialties, primarily medical, which should be resolved.

The transformations under way have been conceived as a comprehensive, integrated process, a strategy recognized worldwide as key to successful health system reform: achieving a broader health system vision involves thinking not just about its components-such as financing, institutions, and technology-but also about interrelationships among these.[17]

Geography has a special significance and is directly associated with multiple objective and subjective factors decisive in implementing and strengthening these transformations in Cuban health services. Information from documents and other sources concerning the current process for "Reorganization, Consolidation and Regionalization of Health Services" in the country maintain that regional data are taken into account.

This process, intimately linked to geography, population distribution and settlement characteristics, should have defined not only population size for primary level institutional catchment areas, but also distances between these services and each community or neighborhood, and the availability of transportation to the redistrib- 
uted services. That is, true accessibility, not simply distance, can be a crucial factor, given constraints on public transportation-more severe in some communities than others-and the fact that the price of private transport is beyond the means of many families.

According to service location theory, distribution or redistribution of any service always leaves people in one area at a relative advantage and those in another at a relative disadvantage. At this point in history, health services, which are entirely government funded, must reach an "optimal distribution" by balancing economic rationalization with equity, the latter term considered by the Cuban population as strictly synonymous with equality.

Criteria that may have been decisive in the health sector revolution of the early 2000s include differences in regional and population-related context; location in relation to other services; service accessibility; and population health status, problems, and needs, inter alia. However, these were handled without overriding budgetary restrictions, or at least without the priority currently imposed by economic rationalization.

In addition to this, policies, standards, and action strategies in many sectors have been implemented equally among all regions, based on a faulty notion of equity. In distribution of health resources and services, especially those related to more modern technology, defining parameters for equitable distribution is much more complicated without some sacrifice of the strong humanitarian component and political will that motivated previous distributions. The idea now is not to have services closer to the people, but instead to have people travel to services at locations assigned to them.

The current complexity is intertwined not only with the population's geographic distribution within municipalities, but also with these locales' different economic and social contexts. Although this is not intended to frustrate exercise of acquired rights, the relative distance of some services could create a new source of dissatisfaction.

Raising awareness about the risks of using high-tech equipment and of self-medication, or about the benefits of natural and traditional medicines-also described in sectoral policy reform guidelines-cannot be done quickly. It requires educational interventions and positive individual or family experiences-either direct or convincing-with these themes. The media's public service announcements aimed at changing acquired behaviors may in fact have results contrary to those expected. There is not always a direct relationship between an increase in services and service quality, or vice versa, or between expected quality and public perception of quality, especially when the high expectations of primary health care quality-built up over more than 20 yearshave been shaken.

In the process of transformation, regional differences can be expected; quality of care will not be the same everywhere, nor will there be equal satisfaction with the same services in two different regions. Obviously, expectations are higher in the capital, particularly for high-tech services, than in the mountainous areas of eastern Cuba. Along with health service administration, other sciences-such as economics, geography, sociology, psychology, anthropology and statistics-will have much to contribute to the complex undertaking of issues of distribution and equity, both theoretically and practically, not only in the sector under our purview, but also in others involved in the public's health.

\section{FINAL CONSIDERATIONS}

The proposed health sector policy guidelines,[1] as well as the health service reorganization, consolidation and regionalization processes under way, signify that we are facing new changes in Cuba's NHS aimed at reducing sector costs in the short term, a phenomenon already observed in recent years with considerable savings in several spheres.

Improvements in service quality included in the health reform policy guidelines and in public satisfaction will not happen as quickly, and to a certain extent will be dependent on improving the material and spiritual living conditions of the two human components of the system, each participating in their dual roles: service provider-citizen and patient-citizen.

Conscientious attention to these components and their firm linkage to the complex relations established among finance, organization and management will be critical to progress in recovering services, improving care and ensuring lasting achievements in health care. Health is not only a specific sector of public administration: it is a high-priority social goal. Cuba has shown abundant evidence of progress toward this goal, which cannot be seen just as better statistics on important global health indicators, but as the result of a strategy and the thoroughgoing application of essential public health principles.[18]

In a 2006 interview in Temas magazine, Francisco Rojas Ochoa, one of the country's most important public health professionals, described the main stages of Cuba's health care models:

"...an initial one, still not well described, of the comprehensive polyclinic; that of the community polyclinic; and family medicine, which appears to be starting to go the way of the previous ones, reaching a point where it does not meet all needs. The model is reaching its limits and we don't yet know how the new one will evolve."[19]

At the interviewer's request, Rojas Ochoa offered his hypothesis on what might occur:

"I would hope for —I don't know if this is what will happen or not-something closely tied to training a physician who pays more attention to the social dynamics of health and disease. More health promotion... greater attention to social problems that affect human health... It's important that the new model not worship modern technology so much: we should ground ourselves more in the old ways of doing things that are so effective, such as clinical skills."[19]

More recently, in a proactive approach, Rojas Ochoa drafted ten "necessary corrections,"[20] almost entirely consistent with the NHS transformation measures that the Ministry of Public Health would put forward only a few months later.

Rojas Ochoa's "necessary corrections," included in the document we have commented on above (Necessary Transformations in the Public Health System)[12] differ fundamentally in the importance this public health professional places on the need to motivate those who perform their daily duties heroically, both on missions abroad and in Cuba, and in his pronounced priority accorded to the training and improvement of human resources for health. 
His proposal highlights the need to give priority to the population's social problems and to motivate health workers, among other aspects.

Strengthening health promotion (also included in the sector policy guidelines) and all actions associated with it requires close and harmonious relationships between providers and beneficiaries, perhaps more so than in other sectors. Obviously, health sector policies are not enough to protect, improve or maintain the population's health. This requires integration of all sectors' policies and intersectoral action-well recognized but still ripe for improvement, and decisive for bettering social health.

The humanist essence of Cuba's social system will not vary, just as it has not in other difficult circumstances. Together with many other objectives, in particular that of modernizing its economic model, Cuba will certainly manage to preserve and improve population health.

Advances in nutrition, housing and sanitation; stress reduction; job satisfaction; and many other components that determine the social construction of health will be attained to the degree that the country makes progress in implementing many of its political and economic guidelines, not just those in the health sector.

The NHS faces the need to reconcile economic rationalization and quality while maintaining free and universal coverage. At the same time it must revamp the concept of equitable resource and service distribution, and encourage people to reconfigure their perceptions and expectations of health care. $-1 /$ -

\section{REFERENCES}

1. Partido Comunista de Cuba. Lineamientos de la política económica y social del Partido y la Revolución. 18 Apr 2011:24. Spanish.

2. Dirección Nacional de Estadísticas. Sistema de Salud [Internet]. La Habana: Ministerio de Salud Pública; 1998 Dec [cited 2010 Dec 25]. Available from: http://www.sld.cu/sistema_de_salud/ estrategias.html. Spanish.

3. Castro R. Discurso pronunciado en la clausura de la Asamblea Nacional del Poder Popular, en el Palacio de Convenciones, 20 Dec 2009. Periódico Granma [Internet]. 21 Dec 2009 [cited 2010 Dec 25]. Available from: http://www.cuba .cu/gobierno/rauldiscursos/2009/esp/r201209e .html. Spanish.

4. Chang M, Alemán ML, Cañizares MP, Ibarra AM. Satisfacción de los pacientes con la atención médica. Rev Cubana Med Gen Integr [Internet]. 1999 [cited 2011 Nov 28];15(5):541-7 Available from: http://scielo.sld.cu/scielo.php?script=sci _arttext\&pid=S0864 -21251999000500009\&lng= es\&nrm=iso\&tlng=es. Spanish.

5. Suárez JJ. El sistema de salud en Cuba. Desafíos hacia el año 2000. Rev Cubana Salud Pública [Internet]. 1997 [cited 2010 Dec 25];23(1-2):5-16. Available from: http://scielo .sld.cu/scielo.php?script=sci_arttext\&pid=S08 64-34661997000100001\&lng=es\&nrm=iso\&tlng =es. Spanish.

6. Luna EM, Sierra DP, Pérez Gandul SL. La transformación del policlínico en Cuba de cara al siglo XXI. Rev Cubana Med Gen Integr [Internet]. 2009 [cited 2010 Dec 25];25(2). Available from: http://scielo.sld.cu/scielo.php?script=sci _arttext\&pid=S0864-21252009000200016\&lng= es\&nrm=iso\&tlng=es. Spanish.

7. García J. Sobrevivirán los niveles de atención a la revolución de la salud pública cubana. Rev Cubana Salud Pública [Internet]. 2006 [cited 2010 Dec 25];32(1). Available from: http://scielo .sld.cu/scielo.php?script=sci_arttext\&pid=S08 64-34662006000100014\&lng=es\&nrm=iso\&tlng =es. Spanish.

8. Terrero A. Otra vuelta de rosca. Revista Bohemia, 24 Mar 2008.

9. Edith D, Terrero A. Salud. ¿Dónde están los médicos? Revista Bohemia Edición No. 6, del 16 de marzo de 2007. Spanish.

10. Ministerio de Salud Pública. Anuario Estadístico de Salud 2009. La Habana: MINSAP; 2010. Spanish.

11. Ministerio de Salud Pública. Anuario Estadístico de Salud 2010. La Habana: MINSAP; 2011. Spanish

12. Ministerio de Salud Pública. Transformaciones necesarias en el Sistema de Salud Pública. La Habana: MINSAP; 2010. Spanish.

13. González R. Emprenden reordenamiento del sistema de Salud en Villa Clara. Periódico Vanguardia, 9 Nov 2010. Spanish.

14. Leyva DF. Revitalizada la medicina familiar en Cienfuegos con la reapertura de nuevos consultorios. Perlavisión, 6 Dec 2010. Spanish.
15. González R. Declarados listos los consultorios del médico y la enfermera de la familia en Villa Clara. Periódico Vanguardia, 3 Dec 2010. Spanish.

16. De la Osa. Hacia la racionalidad en la provincia de La Habana. Periódico Granma [Internet]. 5 Oct 2010 [cited 2011 Nov 28]. Available from: http://www.granma.cubaweb.cu/2010/10/05 /nacional/artic01.html. Spanish.

17. Frenk J. The Global Health System: Strengthening National Health Systems as the Next Step for Global Progress. PLoS Med [Internet]. Jan 2010 [cited 2011 Nov 28];7(1). e1000089. doi:10.1371/journal.pmed.1000089. Available from: http://www.plosmedicine.org larticle/info\%3Adoi\%2F10.1371\%2Fjournal .pmed.1000089;

18. Cooper RC, Kennelly JF, Orduñez GP. Health in Cuba. Internat J Epidemiol. 2006;35:817-24.

19. Rodríguez Oliva LI. Modelos de salud en Cuba. Habla un protagonista. Entrevista a Francisco Rojas Ochoa. Revista Temas. 2006;(47):35-43. Spanish.

20. Rojas Ochoa F. Rectificaciones necesarias [Internet]. 2010 [cited 2010 Sep 6]. Available from: http://articulos.sld.cu/revsalud/category /primero_en_la_web/. Spanish.

\section{AUTHOR}

Luisa Iñiguez Rojas, Center for the Study of Human Health and Wellbeing, University of Havana, Cuba. 